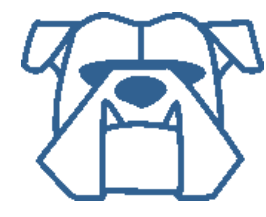

Kettering University Digital Commons@ Kettering University

\title{
Extracting vibration characteristics of a guitar using finite element, modal analysis, and digital image correlation techniques
}

Kiran Patil

Kettering University

Javad Baqersad

Kettering University

Daniel Ludwigsen

Kettering University

Yaomin Dong

Kettering University

Follow this and additional works at: https://digitalcommons.kettering.edu/physics_facultypubs

Part of the Acoustics, Dynamics, and Controls Commons, and the Physics Commons

\section{Recommended Citation}

Patil, Kiran; Baqersad, Javad; Ludwigsen, Daniel; and Dong, Yaomin, "Extracting vibration characteristics of a guitar using finite element, modal analysis, and digital image correlation techniques" (2016). Physics Publications. 35.

https://digitalcommons.kettering.edu/physics_facultypubs/35 


\title{
(s). Proceedings of Meetings on Acoustics
}

Volume 29

http://acousticalsociety.org/

\section{2nd Meeting of the Acoustical Society of America}

Honolulu Hawaii

28 November-2 December 2016

\section{Structural Acoustics and Vibration: Paper 3pSA8}

\section{Extracting vibration characteristics of a guitar using finite element, modal analysis, and digital image correlation techniques}

Kiran Patil and Javad Baqersad

Mechanical Engineering Department, Kettering University, 1700 University Ave, Flint, MI; pati5726@kettering.edu; jbaqersad@kettering.edu

\section{Daniel Ludwigsen}

Physics Department, Kettering University, 1700 University Ave, Flint, MI; dludwigs@kettering.edu

\author{
Yaomin Dong \\ Mechanical Engineering Department, Kettering University; 1700 University Ave, Flint, MI; \\ ydong@kettering.edu
}

The sound quality generated by the guitar depends on the vibration characteristics (i.e. natural frequencies and mode shapes) of this instrument. Thus, it is of particular interest to the guitar manufacturers to be able to obtain global information about the characteristics of the guitar. Traditional sensors can only measure at discrete locations. However, digital image correlation (DIC) can measure full-field data on the surface of the structure. In the current paper, a finite element (FE) model of a guitar with free boundary configurations was developed using quadratic solid elements. An eigensolution was performed on the FE model to determine its natural frequencies and mode shapes. In order to validate the numerical results, a modal impact hammer test was performed on the instrument in a free configuration. Furthermore, a measurement was performed on the guitar using the DIC technique. In this measurement as well, the guitar was suspended in a free configuration, but was driven using a broadband acoustic excitation generated by a sound source. The response of the guitar to the excitation was recorded using a pair of high-speed cameras. The recorded images were processed to extract the natural frequencies and mode shape of the guitar. 


\section{INTRODUCTION}

The sound quality of a guitar depends on the structural mode shapes and the interaction between different components of the guitar. After a string is excited, the vibrations of the strings are transferred to the body of the guitar, and these vibrations interact with the surrounding air to generate the acoustic output. Thus, structural modes are critical in the overall sound quality of guitars, and it is desirable for guitar designers and manufacturers to have a good understanding of those modes. Recent modeling and experimental efforts (see [1-4]) have demonstrated that efforts to model the guitar body always need to be validated by measurements.

Conventionally, mode shapes of structures have been extracted using contact-based sensors such as accelerometers $[5,6]$. These sensors have also been used to measure the vibrations of the guitar [7]. Elejabarrieta et al. [2] used accelerometers to perform an experimental modal analysis on the soundboard of a guitar during its various stages of construction. Curtu et al. [8] also performed several experimental modal measurements on different types of classical guitar bodies. These sensors can be easily implemented and can work up to high frequency ranges while providing a good signal-to-noise ratio [9]. However, they cannot provide full-field data about the structure, only responses at selected points.

Non-contact measurement methods have recently been used in the vibration analysis and structural health monitoring [10-13]. The laser Doppler vibrometer is used extensively for vibration measurement and for monitoring the dynamic response of structures [14], because it can measure up to very high frequencies. However, this technique is very time-consuming and expensive. Digital Image Correlation (DIC) is a state of the art technique that has recently been used in the area of structural dynamics $[12,15-23]$. This technique can provide full-field results on the visible surface of the structure. The technique uses a pair of high speed cameras and image processing algorithms to track patterns and to find deformations of structures. The technique has been applied to monitor vibrations of wind turbine blades [24-28], helicopter rotors [29-31], and civil structures [32]. Using this technique to measure mode shapes of a guitar can provide valuable information and has not been explored by the scientific community.

The current study explores the vibration characteristics of a guitar using the impact hammer modal testing and digital image correlation technique, as well as a finite element model of the guitar to better understand its mode shapes.

\section{EXTRACTING VIBRATION CHARACTERISTICS OF A GUITAR USING FINITE ELEMENT ANALYSIS}

A CAD model of a small-scale toy guitar with many of the intricate details was constructed. This model was then meshed with quadratic shell elements. The material property assigned to the finite element model was Acrylite, as the toy guitar body is some type of plastic. An eigensolution was then performed on the model using the finite element solver to obtain the natural frequency and mode shapes of the guitar. Figure 1 shows the obtained mode shapes and natural frequencies of the guitar. 


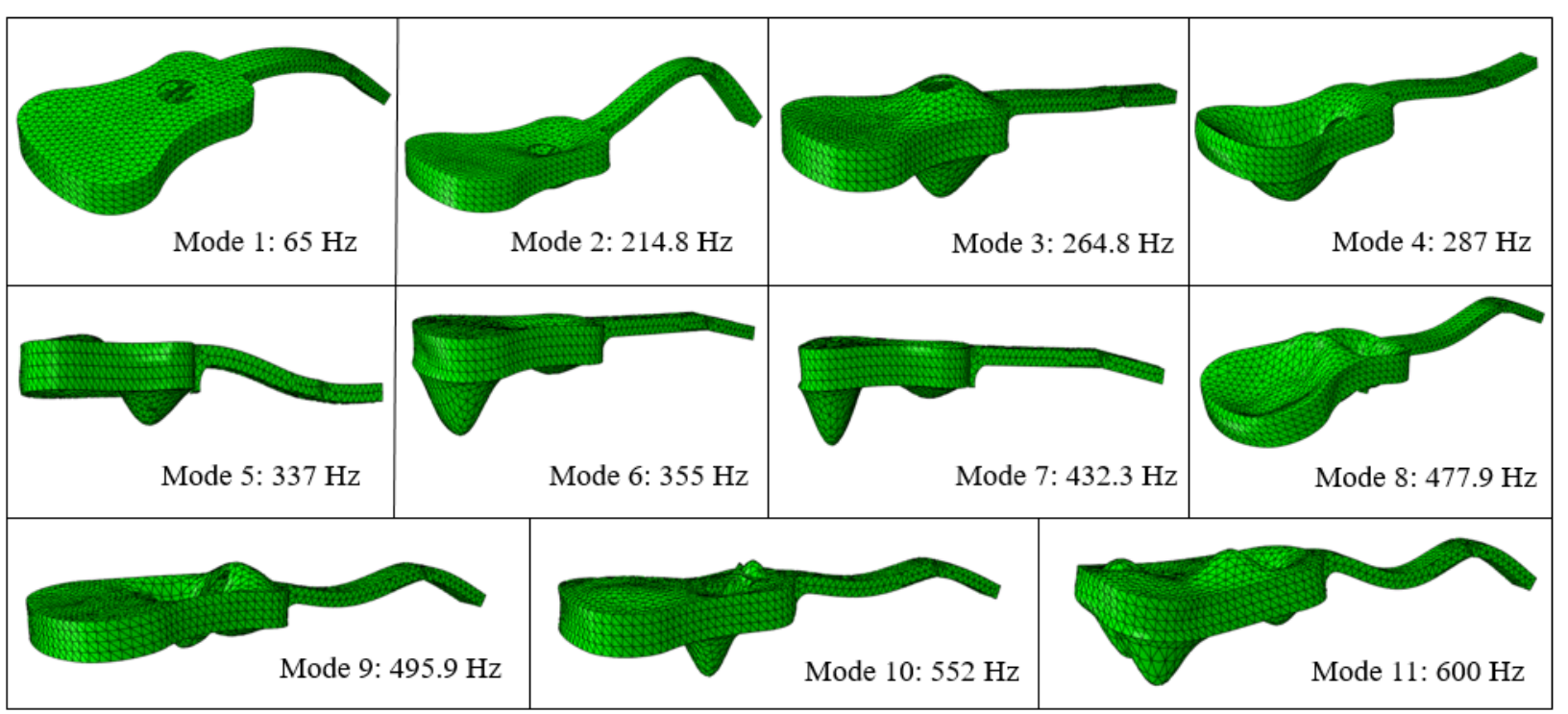

Figure 1. Mode shapes of a toy guitar obtained using the finite element analysis

\section{EXTRACTING VIBRATION CHARACTERISTICS OF THE GUITAR USING IMPACT HAMMER MODAL TESTING}

Figure 2 shows the experimental setup to perform the modal testing on the guitar in a free-free condition. The guitar was suspended in a free-free condition using rubber bands. The entire guitar was divided into 89 measurement points. The guitar was excited at these points using an impact hammer, and the response was measured using three uni-axial accelerometers, also located at measurement points. LMS Test.Lab impact testing software was used to collect and analyze the data. A bandwidth of $1000 \mathrm{~Hz}$ was analyzed, well within the range of good response using a metal tip to excite the guitar. A resolution of $0.5 \mathrm{~Hz}$ was used to perform the experiment. Five frequency response functions were averaged for each measurement point. The power spectrum density and the coherence plots were used as the qualitative measure for every measurement. The obtained FRFs were plotted using the LMS Polymax stability diagram which gave the mode shapes of the guitar (see Figure 3).

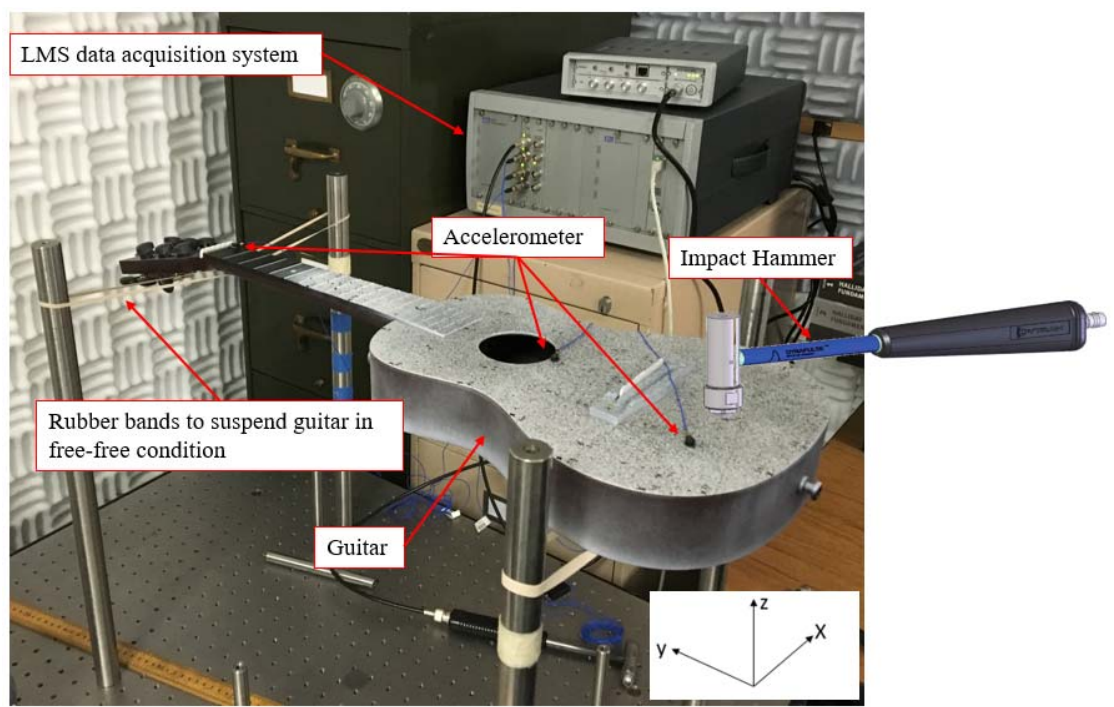

Figure 2. Experimental setup to obtain the mode shapes of the guitar. 


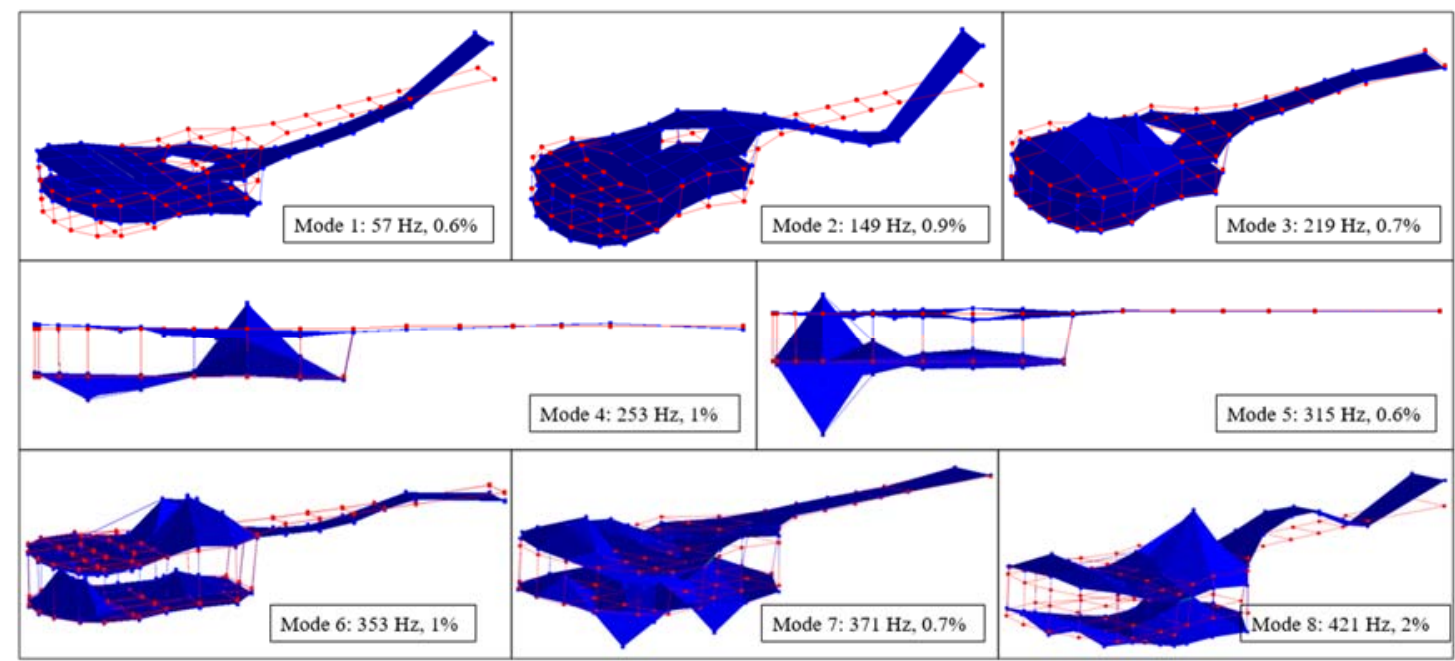

Figure 3. Mode shapes of the guitar obtained using experimental modal analysis

\section{EXTRACTING VIBRATION CHARACTERISTICS OF THE GUITAR USING DIGITAL IMAGE CORRELATION}

Figure 4 shows the experimental setup to extract the mode shapes of the guitar using digital image correlation. The guitar is suspended in a free-free condition using layers of foam. The guitar is excited by a 1-inch horn driver placed underneath the guitar. The response is measured with a pair of high speed cameras. To measure the response using digital image correlation, a speckle pattern is applied to the guitar (see Figure 4). The Vic-3D software package is used to process the data and obtain the natural frequency of the guitar.

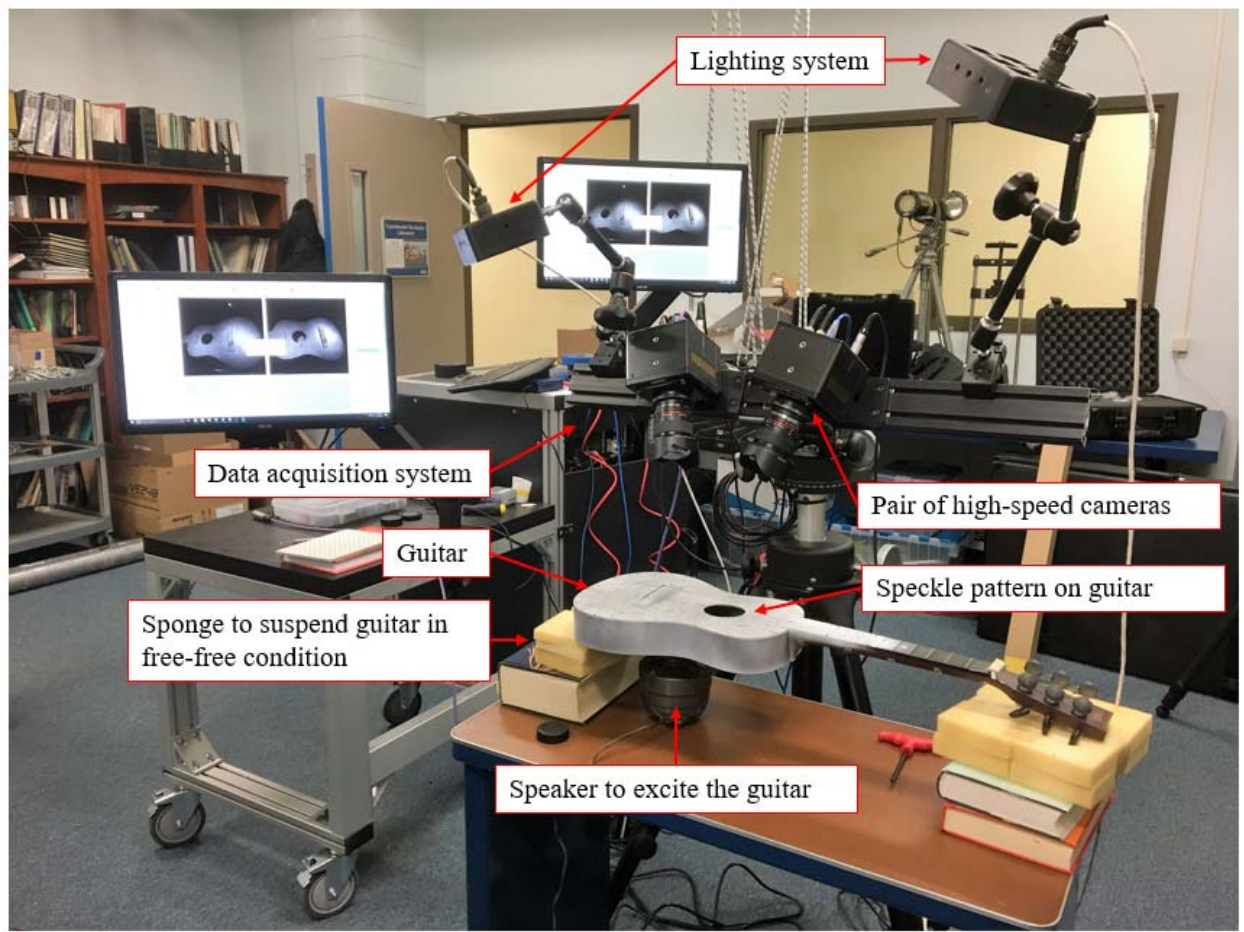

Figure 4. Experimental setup to extract the mode shapes of guitar using digital image correlation 
Figure 5 shows the Fast Fourier Transform (FFT) of the response of the guitar measured using the DIC system. Two trials were performed for this test. In the first trial, a distinctive peak at 152.3 $\mathrm{Hz}$ was obtained. In the second trial, the resonant frequency at $219 \mathrm{~Hz}$ was extracted. The peaks in the FFT represent the natural frequencies of the guitar. Figure 6 shows the obtained operating mode shapes of the guitar using the digital image correlation technique. As can be seen, the two modes of the guitar associated with the resonant frequencies at $152.3 \mathrm{~Hz}$ and $219.0 \mathrm{~Hz}$ were extracted using the DIC technique. For future work, the authors are planning to perform measurements on the guitar to extract its higher order modes.
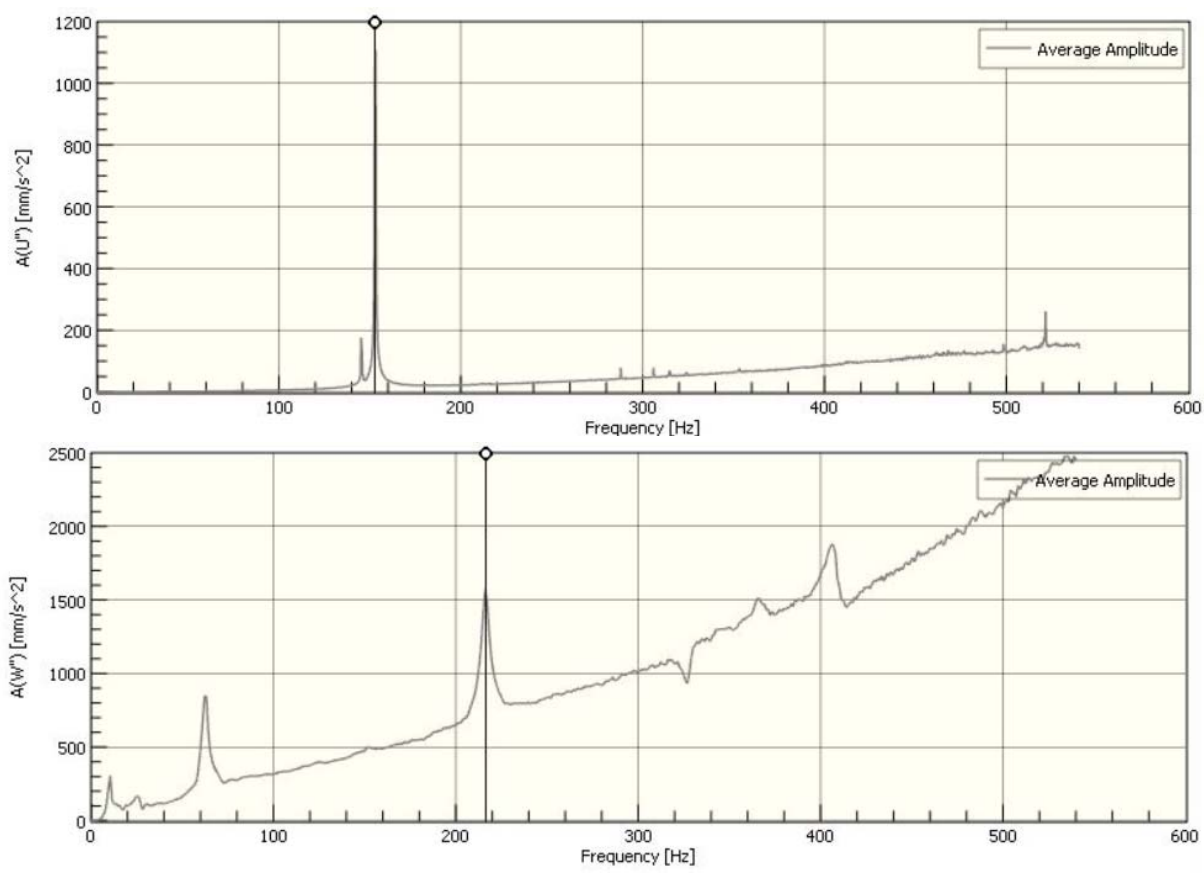

Figure 5. Fast Fourier transform plots of the measured response obtained by processing the images captured with a pair of high speed cameras in two trials. The top image shows the FFT plot used to obtain resonant frequency at $152.3 \mathrm{~Hz}$ and the bottom image shows the FFT plot used to obtain the resonant frequency at $219 \mathrm{~Hz}$.

\section{CORRELATION ANALYSIS}

A comparison between the FE mode shapes and mode shapes extracted using Experimental Modal Analysis (EMA) shows that there are some similarities and dissimilarities between the obtained resonant frequencies and mode shapes. The differences between the results can be attributed to the deviations in the geometry and material property modeling of the guitar. The CAD model was developed using dimensions measured with a caliper. For more accurate results, the CAD model needs to be modeled using scanned data. The neck of the guitar has a complex curvature, which could not be measured using our available tools. Thus, an estimate geometry of the neck of the guitar was modeled; this is why some of the mode shapes that contains neck deforms show less correlations (e.g. Mode 2 is $149 \mathrm{~Hz}$ in EMA data, while FEA shows the mode at $220 \mathrm{~Hz}$ ). Furthermore, Acrylite's material properties were applied to the guitar model. To improve the accuracy of the model, a material testing needs to be performed to extract accurate elastic properties for the guitar body. On the other hand, the FE model provided a general understanding of the modes in the guitar. 

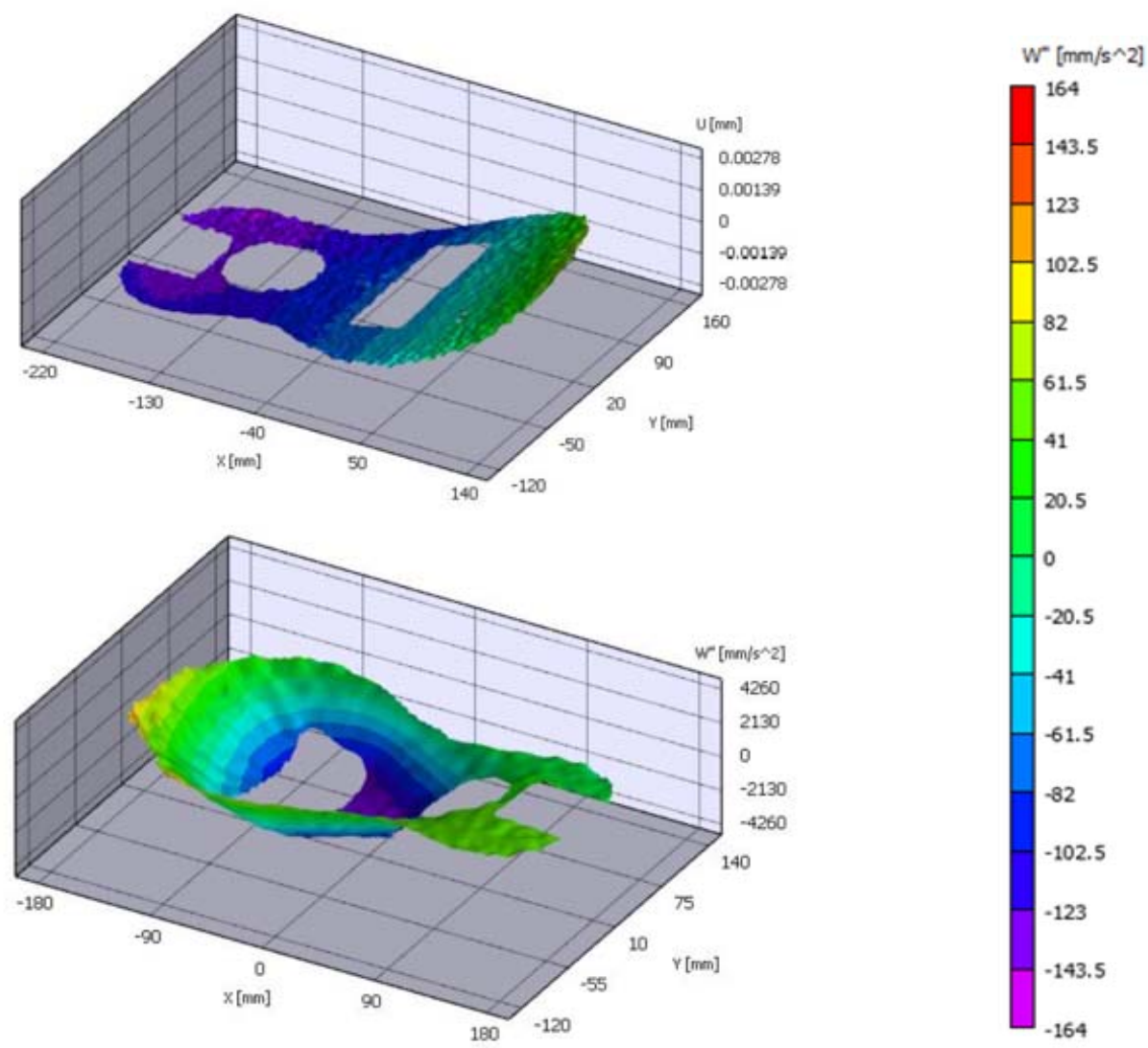

Figure 6. Operating mode shapes of the guitar obtained using DIC for the resonant frequency at $152 \mathrm{~Hz}$ (top) and $219 \mathrm{~Hz}$ (bottom).

The EMA and DIC results show a very good correlation between the extracted modes. The modes extracted using DIC at $152.3 \mathrm{~Hz}$ and $219 \mathrm{~Hz}$ are respectively located at frequencies of $149 \mathrm{~Hz}$ and $219 \mathrm{~Hz}$ in the EMA results. The small changes between these two modes can be attributed to the free-free configurations in the two measurements. Due to small displacements occurring in the guitar, extracting higher order modes using DIC is challenging. However, by using data processing tools and averaging the data, extracting higher order modes would be possible.

\section{CONCLUSION}

A comparison between the three techniques used to extract mode shapes of the guitar lead to the following conclusions:

1. The finite element approach can be used to extract mode shapes of the guitar. This technique is less expensive than experimental measurements. However, the results need to be validated.

2. The experimental modal analysis is a robust technique to obtain the mode shape of the guitar. This technique has a wide frequency range and can be easily implemented. However, this technique can only provide mode shapes at discrete points. Furthermore, the sensors might induce mass loading effects on the structure.

3. The digital image correlation technique provide invaluable information about dynamics of the structure. It can measure displacement at million points on the structure to provide full- 
field results. However, the measured data using DIC usually contains noise, and it is challenging to measure higher order modes using this approach. With the advances of the camera technology and image processing tools, this technique has a great potential to be used in the structural dynamics area.

\section{REFERENCES}

[1] G. Derveaux, A. Chaigne, P. Joly, E. Bécache, Time-domain simulation of a guitar: Model and method, The Journal of the Acoustical Society of America, 114 (2003) 3368-3383.

[2] M. Elejabarrieta, A. Ezcurra, C. Santamarıa, Evolution of the vibrational behavior of a guitar soundboard along successive construction phases by means of the modal analysis technique, The Journal of the Acoustical Society of America, 108 (2000) 369-378.

[3] M. Elejabarrieta, A. Ezcurra, C. Santamaria, Coupled modes of the resonance box of the guitar, The Journal of the Acoustical Society of America, 111 (2002) 2283-2292.

[4] D. Ludwigsen, Spectral character of the resonator guitar, The Journal of the Acoustical Society of America, 134 (2013) 3994-3994.

[5] J. Baqersad, P. Poozesh, C. Niezrecki, P. Avitabile, Comparison of modal parameters extracted using MIMO, SIMO, and impact hammer tests on a three-bladed wind Turbine, Topics in Modal Analysis II, Volume 8, Springer, 2014, pp. 185-197.

[6] P. Avitabile, R. Singhal, B. Peeters, J. Leuridan, Modal parameter estimation for large, complicated MIMO tests, Sound and Vibration, 40 (2006) 14.

[7] J. Woodhouse, Plucked guitar transients: Comparison of measurements and synthesis, Acta Acustica united with Acustica, 90 (2004) 945-965.

[8] I. Curtu, M. Stanciu, N. Cretu, I. Rosca, Modal analysis of different types of classical guitar bodies, Proceedings of the 10th WSEAS International Conference on Acoustics \& Music: Theory \& Applications-AMTA09 (ISTP/ISI Proceeding of Thomson Scientific-Institute for Scientific Information), 2009, pp. 23-25.

[9] A. Sarrafi, Z. Mao, Probabilistic uncertainty quantification of wavelet-transform-based structural health monitoring features, SPIE Smart Structures and Materials + Nondestructive Evaluation and Health Monitoring, International Society for Optics and Photonics, 2016, pp. 98051N-98051N-98010.

[10] P. Poozesh, J. Baqersad, C. Niezrecki, E. Harvey, R. Yarala, Full Field Inspection of a Utility Scale Wind Turbine Blade Using Digital Image Correlation, CAMX, Orlando, FL, 2014.

[11] P. Poozesh, K. Aizawa, C. Niezrecki, J. Baqersad, M. Inalpolat, G. Heilmann, Structural health monitoring of wind turbine blades using acoustic microphone array, Structural Health Monitoring, 0 1475921716676871. doi:doi:10.1177/1475921716676871.

[12] D. Feng, M.Q. Feng, Experimental validation of cost-effective vision-based structural health monitoring, Mechanical Systems and Signal Processing, 88 (2017) 199-211. doi:http://dx.doi.org/10.1016/j.ymssp.2016.11.021.

[13] S. Tashakori, A. Baghalian, M. Unal, H. Fekrmandi, D. McDaniel, I.N. Tansel, Contact and non-contact approaches in load monitoring applications using surface response to excitation method, Measurement, 89 (2016) 197-203.

[14] A. Baghalian, S. Tahakori, H. Fekrmandi, M. Unal, V. Senyurek, D. McDaniel, I. Tansel, Implementation of the Surface Response to Excitation Method for Pipes, Mechanics of Composite and Multi-functional Materials, Volume 7, Springer, 2017, pp. 261-266.

[15] J. Baqersad, P. Poozesh, C. Niezrecki, P. Avitabile, Photogrammetry and optical methods in structural dynamics - A review, Mechanical Systems and Signal Processing. doi:http://dx.doi.org/10.1016/j.ymssp.2016.02.011. 
[16] P. Poozesh, J. Baqersad, C. Niezrecki, P. Avitabile, E. Harvey, R. Yarala, Large-area photogrammetry based testing of wind turbine blades, Mechanical Systems and Signal Processing, (2016). doi:http://dx.doi.org/10.1016/j.ymssp.2016.07.021.

[17] P. Poozesh, J. Baqersad, C. Niezrecki, P. Avitabile, A Multi-Camera Stereo DIC System for Extracting Operating Mode Shapes of Large Scale Structures, SEM Annual Conference on Experimental and Applied Mechanics, Costa Mesa, CA, June 2015.

[18] P. Poozesh, D.D. Sabino, J. Baqersad, P. Avitabile, C. Niezrecki, Practical Techniques for Scaling of Optically Measured Operating Deflection Shapes, Proceedings of the 34th IMAC, A Conference and Exposition on Structural Dynamics Springer International Publishing, Springer International Publishing, Orlando, FL, March, 2016, pp. 1-17.

[19] P. Poozesh, A. Sarrafi, C. Niezrecki, Z. Mao, p. Avitabile, Extracting high frequency operating shapes from 3D DIC measurements and phased-based motion magnified images iDICs, Conference and Workshop/SEM Fall Conference, Springer, Philadelphia, PA, USA, 2016.

[20] M. Hagara, R. Huňady, F. Trebuňa, P. Pavelka, The Analyses of Large Displacement Pendulum Movement Using High-Speed Digital Image Correlation and Matlab/Simulink, American Journal of Mechanical Engineering, 4 (2016) 406-412.

[21] Y. Yang, C. Dorn, T. Mancini, Z. Talken, G. Kenyon, C. Farrar, D. Mascareñas, Blind identification of full-field vibration modes from video measurements with phase-based video motion magnification, Mechanical Systems and Signal Processing, 85 (2017) 567-590.

[22] P. Castellini, P. Chiariotti, M. Martarelli, E.P. Tomasini, Digital Image Correlation for Timing Belts Dynamic Characterization: Potentials and Critical Aspects, in: E. Wee Sit (Ed.) Sensors and Instrumentation, Volume 5: Proceedings of the 34th IMAC, A Conference and Exposition on Structural Dynamics 2016, Springer International Publishing, Cham, 2016, pp. 113-121. doi:10.1007/978-3-319-29859-7_12.

[23] A. Lavatelli, E. Zappa, Modeling Uncertainty for a Vision System Applied to Vibration Measurement, IEEE Transactions on Instrumentation and Measurements, 65 (2016) 1818 1826.

[24] P. Poozesh, J. Baqersad, C. Niezrecki, P. Avitabile, E. Harvey, R. Yarala, Large-area photogrammetry based testing of wind turbine blades, Mechanical Systems and Signal Processing. doi:http://dx.doi.org/10.1016/j.ymssp.2016.07.021.

[25] J. Baqersad, P. Poozesh, C. Niezrecki, P. Avitabile, A Noncontacting Approach for Full-Field Strain Monitoring of Rotating Structures, Journal of Vibration and Acoustics, 138 (2016) 031008-031008. doi:10.1115/1.4032721.

[26] J. Baqersad, C. Niezrecki, P. Avitabile, Full-field dynamic strain prediction on a wind turbine using displacements of optical targets measured by stereophotogrammetry, Mechanical Systems and Signal Processing, 62 (2015) 284-295. doi:10.1016/j.ymssp.2015.03.021.

[27] J. Baqersad, C. Niezrecki, P. Avitabile, Extracting full-field dynamic strain on a wind turbine rotor subjected to arbitrary excitations using 3D point tracking and a modal expansion technique, Journal of Sound and Vibration, 352 (2015) 16-29. doi:10.1016/j.jsv.2015.04.026.

[28] H. Zhou, H. Dou, L. Qin, Y. Chen, Y. Ni, J. Ko, A review of full-scale structural testing of wind turbine blades, Renewable and Sustainable Energy Reviews, 33 (2014) 177-187.

[29] T. Lundstrom, J. Baqersad, C. Niezrecki, Monitoring the Dynamics of a Helicopter Main Rotor With High-Speed Stereophotogrammetry, Experimental Techniques, (2015). doi:10.1111/ext.12127.

[30] S. Rizo-Patron, J. Sirohi, Operational Modal Analysis of a Helicopter Rotor Blade Using Digital Image Correlation, Exp Mech, 57 (2017) 367-375. doi:10.1007/s11340-016-0230-6. 
[31] S.S. Rizo-Patron, J. Sirohi, Operational modal analysis of a rotating cantilever beam using high-speed digital image correlation, 57th AIAA/ASCE/AHS/ASC Structures, Structural Dynamics, and Materials Conference, 2016, pp. 1957.

[32] S. Rajaram, P. Vanniamparambil, F. Khan, M. Bolhassani, A. Koutras, I. Bartoli, F. Moon, A. Hamid, P. Benson Shing, J. Tyson, Full-field deformation measurements during seismic loading of masonry buildings, Structural Control and Health Monitoring, (2016). 